\title{
Singlet Oxygen Production by Organic Matter and Disintegration of Pathogens and Pollutants during Wastewater Treatment: How Important?
} Saurabh Jyoti Sarma, Ratul Kumar Das and Satinder Kaur Brar*

\author{
Institut National de la Recherche Scientifique, Centre Eau, Terre \& Environnement, Québec (QC), Canada
}

Electronically excited, highly reactive state of molecular oxygen is known as singlet oxygen. Apart from different other methods; singlet oxygen is mainly produced by irradiation of molecular oxygen in presence of photosensitizer pigments such as rose Bengal or methylene blue. Because of its potential applications in many fields including wastewater treatment, singlet oxygen remains to be one of the mostly explored research subjects of recent years. Singlet oxygen can be used as treatment mean against both pathogens and toxic organic pollutants present in wastewater [1]. For example, numbers of reports are available on oxidation of phenol and its derivatives, either in organic solvents or in aqueous solution, by the action of photosensitizer induced singlet oxygen [2]. Similarly, Schäfer et al. [3] have investigated the inactivation of bacteria, such as Escherichia coli or Deinococcusradiodurans using photosensitizer technology involving singlet oxygen [3]. In addition to commonly used photosensitizer pigments, aromatic hydrocarbons (napthalenes, anthracenes, biphenyls) have also been evaluated for possible application as photosensitizer [2]. Similarly, a range of quinones can also work as sensitizers for singlet oxygen $[2,4]$. Even, the organic matter of an aquatic system has the potential to work as the inherent photosensitizer to support the formation of singlet oxygen as well as other reactive oxygen species [1]. Similarly, Dalrymple et al. [5] also have reported singlet oxygen production by aquatic dissolved organic matter [5]. Wastewater contains all these different types of photosensitizers; hence, degradation of different pollutants and elimination of pathogens by singlet oxygen produced during wastewater treatment process is a likely phenomenon. However, singlet oxygen has very short lifetime and they may also be involved in other intermolecular interactions, which are not relevant in pollutant degradation or pathogen inactivation [6]. Likewise, yield of singlet oxygen depends on the oxygen concentration [7]. However, the oxygen demand of wastewater treatment process is already very high. Therefore, whether the oxygen left after microbial utilization will be sufficient to generate the required amount of singlet oxygen for a significant response or not, is a question. Likewise, due to irradiation, chromophoric dissolved organic matter may be degraded to be more available for microbial utilization and it may further enhance the bacterial growth [8], including pathogens. Thus, considering additional cost involved, in the case of artificially irradiated wastewater treatment process, the purpose of pathogen inactivation and pollutant degradation using singlet oxygen may not be very effective. In this context, Mostafa \& Rosario-Ortiz [1] have indicated that the concept of inherent photosensitizer (organic matter) mediated singlet oxygen generation and wastewater treatment may have more practical implication in the case of relatively cost effective sunlight-mediated nonconventional wastewater treatment processes, such as constructed wetlands [1]. Thus, in order to have a better understanding of the role of singlet oxygen in wastewater treatment, actual contribution of naturally produced singlet oxygen, in pathogen inactivation and contaminant degradation during wastewater treatment, should be precisely estimated. Further, possible enhancement of the efficiency of singlet oxygen, by the technique such as artificial irradiation and additional cost involved in such operation, should be determined. Likewise, alternative wastewater treatment processes should be designed, where maximum utilization of natural photosensitization is possible. Finally, based on the techno-economic feasibility of using artificial irradiation, the possibility of using it (in a cost effective way) to complement natural photosensitization, should also be explored.

\section{References}

1. Mostafa S, Rosario-Ortiz FL (2013) Singlet Oxygen Formation from Wastewater Organic Matter. Environ Sci Technol.

2. DeRosa MC, Crutchley RJ (2002) Photosensitized singlet oxygen and its applications. Coordination Chemistry Reviews 233: 351-371.

3. Schäfer M, Schmitz C, Facius R, Horneck G, Milow B, et al. (2000) Systematic Study of Parameters Influencing the Action of Rose Bengal with Visible Light on Bacterial Cells: Comparison Between the Biological Effect and Singlet-Oxygen Production. Photochem Photobiol 71: 514-523.

4. Gutiérrez I, Bertolotti SG, Biasutti MA, Soltermann AT, García NA (1997) Quinones and hydroxyquinones as generators and quenchers of single molecular oxygen. Canadian Journal of Chemistry 75: 423-428.

5. Dalrymple RM, Carfagno AK, Sharpless CM (2010) Correlations between Dissolved Organic Matter Optical Properties and Quantum Yields of Singlet Oxygen and Hydrogen Peroxide. Environmental science \& technology 44 5824-5829.

6. Kuznetsova N (2012) Sensitization of Singlet Oxygen Formation in Aqueous Media. In: Photosensitizers in Medicine, Environment, and Security, Springer, pp. 267-313.

7. Baier J, Maisch T, Maier M, Engel E, Landthaler M, et al. (2006) Singlet oxygen generation by UVA light exposure of endogenous photosensitizers. Biophys $J$ 91: $1452-1459$

8. Sandvik SLH, Bilski P, Pakulski JD, Chignell CF, Coffin RB (2000) Photogeneration of singlet oxygen and free radicals in dissolved organic matter isolated from the Mississippi and Atchafalaya River plumes. Marine Chemistry 69: $139-152$.

*Corresponding author: Satinder Kaur Brar, Institut National de la Recherche Scientifique, Centre Eau, Terre \& Environnement, 490 de la Couronne, Canada, Phone: 1-418-654-3116; Fax: 1-418-654-2600; E-mail: satinder.brar@ete.inrs.ca

Received July 19, 2013; Accepted July 22, 2013; Published July 25, 2013

Citation: Sarma SJ, Das RK, Brar SK (2013) Singlet Oxygen Production by Organic Matter and Disintegration of Pathogens and Pollutants during Wastewate Treatment: How Important? Hydrol Current Res 4: e109. doi:10.4172/2157 7587.1000e109

Copyright: @ 2013 Sarma SJ, et al. This is an open-access article distributed unde the terms of the Creative Commons Attribution License, which permits unrestricted use, distribution, and reproduction in any medium, provided the original author and source are credited. 